\title{
Production Trends in Mature Macadamia Orchards and the Effects of Selective Limb Removal, Side-hedging, and Topping on Yield, Nut Characteristics, Tree Size, and Economics
}

\author{
Lisa McFadyen ${ }^{1,2,3}$, David Robertson ${ }^{1}$, Margaret Sedgley ${ }^{2}$, \\ Paul Kristiansen ${ }^{2}$, and Trevor Olesen ${ }^{1,2}$
}

AdDITIONAL INDEX wORDs. Macadamia integrifolia, Macadamia tetraphylla, pruning

Summary. Yields of macadamia (Macadamia integrifolia, M. tetraphylla, and hybrids) orchards tend to increase with increasing tree size up to $\approx 94 \%$ light interception. Beyond this, there is some indication that crowding leads to yield decline, but the evidence is limited to one site. Increasing tree size and orchard crowding also present numerous management problems, including soil erosion, harvest delays, and increased pest and disease pressure. The aim of this study was to better characterize long-term yield trends in mature orchards and to assess the effects of manual and mechanical pruning strategies on yield, nut characteristics, tree size, and economics. We monitored yield at four sites in mature ' 344 ' and ' 246 ' orchards for up to seven years and confirmed a decline in yield with crowding for three of the sites. There was a small increase in yield over time at the fourth site, which may reflect the lower initial level of crowding and shorter monitoring period compared with the other sites, and highlights the need for long-term records to establish yield trends. Pruning to remove several large limbs from '246' trees to improve light penetration into the canopy increased yield relative to control trees but the effect was short-lived and not cost-effective. Removal of a codominant leader from ' 344 ' trees reduced yield by $21 \%$. Annual side-hedging of ' 246 ' trees reduced yield by $12 \%$ and mechanical topping of ' 344 ' trees caused a substantial reduction in yield of up to $50 \%$. Removal of limbs in the upper canopy to reduce the height of ' 344 ' trees had less effect on yield than topping but re-pruning was not practical because of the extensive regrowth around the pruning cuts. Tree size control is necessary for efficient orchard management, but in this study, pruning strategies that controlled tree size also reduced yield. Research into the physiological response to pruning in macadamia is required to improve outcomes.

$\mathrm{M}$

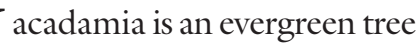
grown in subtropical regions around the world for its edible kernel. The tree grows by recurrent flushing and flower racemes develop in leaf axils between 40 and $140 \mathrm{~cm}$ from the branch apex depending on cultivar and season. Anthesis occurs in early spring (September in Australia) and

\footnotetext{
This work was funded by Horticulture Australia Limited using the Australian macadamia industry levy and matched funds from the Australian Government.

We thank Russell Priddle, Margaret Oldham, Alister Janetzki, Magda Verbeek, and Robyn Andrews for technical assistance; Stephen Morris for advice on and assistance with statistical analysis; and Sherie Ainsbury, Nick Ap Ap, Ken Haselden, Ian Hotson, Cliff James, Ian Mulligan, and Mike Thomas for access to their orchards and for their assistance and cooperation.

${ }^{1}$ New South Wales Department of Primary Industries, Wollongbar Primary Industries Institute, 1243 Bruxner Highway, Wollongbar, NSW 2477, Australia

${ }^{2}$ Faculty of Arts and Sciences, The University of New England, Armidale, NSW 2351, Australia

${ }^{3}$ Corresponding author. E-mail: lisa.mcfadyen@
} dpi.nsw.gov.au. fruit mature $\approx 30$ weeks later, abscise over six months, and are harvested regularly from the orchard floor. Trees may grow to $18 \mathrm{~m}$ (Cull, 1983) and leaf density is high at over 400 leaves $/ \mathrm{m}^{3}$ (Olesen et al., 2011). Australian orchards tend to be planted at 7 or $8 \mathrm{~m}$ between rows and 3 or $4 \mathrm{~m}$ between trees within rows. The trees take several years to come into production, about three years for the most precocious cultivars and six years for the least precocious. Once in production, yields tend to increase with increasing tree size, up to very high levels of orchard light interception $[\approx 94 \%$ (McFadyen et al., 2004)]. At even higher levels of light interception, there is some indication that crowding leads to a decline in yields (McFadyen et al., 2004), although the evidence depends heavily on the yields from one site in a regional study. One challenge in confirming yield decline is the large seasonal variation in yield that reflects a tendency to alternate bearing (Wilkie, 2009).

In addition to the potential for yield decline, tree crowding presents a host of management problems, including loss of groundcover and consequent soil erosion, slow orchard floor drying after rain resulting in harvest delays and deterioration in nut quality, greater pest and disease risk, and a reduced ability to spray trees effectively.

Tree removal has been used in a bid to maintain production in crowded orchards and to alleviate the management problems. However, it is expensive, results in an initial reduction in yield per hectare of $15 \%$ to $50 \%$, and it can take up to 10 years for yield to recover to that of an unthinned orchard (McFadyen et al., 2003, 2005; Robertson et al., 2012). Regularly hedging the sides of small trees maintains light and ventilation to the lower canopy and orchard floor between tree rows and, for nine-year-old trees, caused less yield loss than tree removal (McFadyen et al., 2004). However, as tree height continues to increase, the orchard floor and lower canopy become shaded for most of the day, diminishing the benefit of the open interrow.

Manual pruning of mature trees has been trialed in other tree crops, where orchard crowding is a problem, to reduce intra- and intertree shading

\begin{tabular}{llll}
\hline $\begin{array}{l}\text { Units } \\
\begin{array}{l}\text { To convert U.S. to SI, } \\
\text { multiply by }\end{array}\end{array}$ & U.S. unit & SI unit & $\begin{array}{l}\text { To convert SI to U.S., } \\
\text { multiply by }\end{array}$ \\
\hline 0.4047 & $\mathrm{acre}(\mathrm{s})$ & $\mathrm{ha}$ & 2.4711 \\
0.3048 & $\mathrm{ft}$ & $\mathrm{m}$ & 3.2808 \\
0.0283 & $\mathrm{ft}^{3}$ & $\mathrm{~m}^{3}$ & 35.3147 \\
0.0700 & $\mathrm{ft}^{3} / \mathrm{acre}$ & $\mathrm{m}^{3} \cdot \mathrm{ha}^{-1}$ & 14.2913 \\
2.54 & inch(es) & $\mathrm{cm}$ & 0.3937 \\
25.4 & inch(es) & $\mathrm{mm}$ & 0.0394 \\
0.4536 & $\mathrm{lb}$ & $\mathrm{kg}$ & 2.2046 \\
28.3495 & $\mathrm{oz}$ & $\mathrm{g}$ & 0.0353 \\
1 & $\mathrm{ppm}$ & $\mathrm{mg} \cdot \mathrm{L}^{-1}$ & 1 \\
2.2417 & ton $/ \mathrm{acre}$ & $\mathrm{t} \cdot \mathrm{ha}^{-1}$ & 0.4461
\end{tabular}


to increase or maintain consistent productivity, and in some cases to reduce tree height. Generally, this has involved the removal of several whole limbs as close as possible to the main stem(s) or a lateral branch. In pecan (Carya illinoinensis), the one-off removal of limbs that competed for light with adjacent limbs or trees increased yield in two of three cultivars but only for one season out of three (Lombardini, 2006). In avocado (Persea americana), reducing the number of main scaffold branches in trees from $8-12$ to $6-8$ increased productivity on the remaining branches but yield per tree was similar to that of unpruned trees (Thorp and Stowell, 2001). In sweet orange (Citrus sinensis), removal of two or three large scaffold branches reduced yield with the effect increasing with the weight of fresh wood removed (Kallsen, 2005). In macadamia, manual pruning of six-year-old trees reduced yield in proportion to the severity of pruning (Olesen et al., 2011), but the response to pruning older, more heavily shaded trees has not been reported.

In pecan, annual removal of one or three limbs per tree to reduce tree height from 18 to $9 \mathrm{~m}$ did not reduce yield (Worley, 1991). However, in a companion study, removal of one to three limbs per year to reduce tree height from 18 to 9 or $12 \mathrm{~m}$ decreased yield in both treatments by an average of $21 \%$ over 19 years (Worley and Mullinix, 1997). In avocado trees that were 5 to $8 \mathrm{~m}$ tall before treatment, branches were pruned at their junction with strong lateral growths, at 4 or $6 \mathrm{~m}$. Yields were reduced in trees pruned to $4 \mathrm{~m}$ but not in those pruned to $6 \mathrm{~m}$ (Thorp and Stowell, 2001).

Mechanically pruning the tops of trees or "topping" is an easier and cheaper means of reducing tree height than manual removal of whole limbs. However topping, like side-hedging, involves numerous small cuts that stimulates more post-pruning shoot growth than a few large cuts as accomplished with manual pruning (Mika, 1986). This enhanced shoot growth has the potential to inhibit flowering and fruit development (McFadyen et al., 2011; Mika, 1986; Olesen, 2005). Topping has been extensively tested in citrus (Citrus sp.) and had either no effect on average yield in the seasons after topping (Fucik, 1977, 1988; Kallsen, 2005) or reduced yield (Eissenstat and Duncan,
1992; Fucik, 1977; Morales et al., 2000; Whitney et al., 1983). In some hedging and topping studies in citrus, there were no differences in average yield between pruned and unpruned trees for the years following pruning because pruning mitigated alternate bearing (Bevington and Bacon, 1978; Fucik, 1977; Raciti et al., 1981). Topping in pistachio (Pistacia vera) also mitigated alternate bearing, with topped trees producing similar average yields over six years compared with untopped trees (Ferguson et al., 1995). Hedged and topped pecan trees had lower yields than unpruned trees (Worley, 1985), but there is no information on the impact of topping alone for pecan.

The first aim of this study was to better characterize the long-term trends in macadamia production by continuing to monitor the yields at the two most crowded sites established by McFadyen et al. (2004) and at two other sites that were at a similar stage of crowding. The second aim was to examine the effects of manual and mechanical pruning on yield, nut characteristics, tree size, and economics in crowded orchards. Three pruning experiments were conducted. In the first experiment, the effects of either selective limb removal or side-hedging were quantified, relative to control trees. In the second experiment, mechanically topped trees were compared with untopped control trees. In the third experiment, the effects of either mechanical topping, selective limb removal in the upper canopy to reduce tree height, or the removal of a codominant leader were quantified, relative to control trees.

\section{Materials and methods}

Experiments were conducted in commercial orchards near Lismore (lat. $28.8^{\circ} \mathrm{S}$, long. $153.3^{\circ} \mathrm{E}$ ), in northern NSW, Australia, on deep, well-drained reddish-brown clay loam soils (Morand, 1994). Trees were grafted on seedling rootstocks grown from fruit from ' $\mathrm{H} 2$ ' trees ( $M$. integrifolia) and orchard operations were carried out according to industry guidelines (O'Hare et al., 2004).

EXPERIMENT 1: YIELD SURVEY. Yield was monitored in mature orchards for between four and seven years at four localities, Fernleigh, Tregeagle, Whian Whian, and Eureka. The sites at Fernleigh and Tregeagle had been monitored from 1996 to 2001 as part of a previous yield survey (McFadyen et al., 2004) and were observed in the current study from 2002 to 2005 , providing a total of 10 years for analysis. Sites at Whian Whian and Eureka were in plantings of similar ages and degree of orchard crowding as sites at Fernleigh and Tregeagle and were monitored from 1999 to 2004 and from 1999 to 2005, respectively. Yield and tree dimensions were measured in six plots of three trees at Fernleigh, Tregeagle, and Whian Whian, and six plots of four trees at Eureka. The trees surveyed were all $M$. integrifolia with cultivar ' 344 ' at Fernleigh, Tregeagle, and Whian Whian and '246' at Eureka. Trees were 16 years old at the start of each measurement period except at Tregeagle where they were 14 years old. All trees were unpruned apart from mechanical skirting of the bottom of the canopy required for access of harvest machinery.

In each year, fruit were harvested from the ground between March and September at 4- to 5-week intervals. Fruit were dehusked and samples were taken from each plot to determine moisture content. Yield was expressed as nut-in-shell (NIS) at $10 \%$ moisture content, which is the commercial standard. Row and tree spacings were used to convert yield per plot to yield per hectare.

As in McFadyen et al. (2004), tree volume per hectare was used as an index of orchard crowding. Tree height and canopy width were measured at the beginning of the survey period and tree volume was calculated assuming the shape of the canopy to be an irregular ellipsoid (CharlesEdwards et al., 1986).

EXPERIMENT 2: THE EFFECTS OF SELECTIVE LIMB REMOVAL AND SIDEHEDGING ON 16-YEAR-OLD '246' TREES. This experiment was conducted on '246' trees planted in east-west rows. At the start of the experiment, the trees were 16 years old and, on average, 7.9- $\mathrm{m}$ tall and $7-\mathrm{m}$ wide across the row. Trees had met within the row to form a hedgerow. Treatments were first applied in 1998 and included annual hedging, limb removal, and a control that was unpruned except for regular mechanical skirting of the bottom of the canopy for machinery access, which was applied to all treatments. In the hedged treatment, trees were pruned each year in October 
with a commercial hedging machine. In the first year, one vertical cut was made to each side of the hedgerow. In subsequent years, two cuts were made on each side: a vertical cut on the bottom half of the canopy and a second cut above this, angled slightly toward the center of the row. Hedging removed $\approx 0.3 \mathrm{~m}$ of canopy from each side of the hedgerow. In the limb removal treatment, a chainsaw was used to remove two to three limbs per tree to create windows for light penetration into the canopy. Limbs were removed in Oct. 1998 and July 2001.

The experiment was laid out as a randomized complete block with six replicates over eight rows. Each plot comprised four trees and was buffered by trees receiving the same treatment: one tree on each end of the plot within the row and six trees in adjacent rows on either side of the plot. Row spacing in the orchard varied between 8.0 and $9.0 \mathrm{~m}$ and tree spacing within the row was between 2.7 and $3.9 \mathrm{~m}$. Row and tree spacing were measured for each plot to calculate the plot area, and the treatments were restrictively randomized to plots within the blocks so that treatments had similar plot area distributions. The plot area was used to convert yield per plot to yield per hectare.

Yield data were collected from 1999 to 2005 as described for the yield survey in Expt. 1. In addition, samples of 100 nuts were taken from each plot at each harvest for the determination of nut quality as described in McFadyen et al. (2004). Average nut weight was also determined from the sample and a weighted average based on the total weight of nuts per plot at each harvest was calculated.

Tree height and canopy width were measured in each season before hedging and tree volume was calculated as described in Expt. 1.

The economics of limb removal and hedging were compared with the control using a partial budget of the gross revenues, pruning costs, and costs that vary with yield. These gross margins were calculated for each replicate and year of the trial and their total present value (PV) was calculated using a discount rate of $8 \%$. The $\mathrm{PV}$ calculation takes into account the time value of money by discounting the value of a future sum of money to its present day value. Revenue, in Australian dollars (A\$), for each replicate was determined by sales of NIS at the longterm average price of $\mathrm{A} \$ 2.70 / \mathrm{kg}$ for NIS with a $33 \%$ sound kernel recovery [SKR (Australian Macadamia Society, n.d.)]. The price per kilogram was adjusted up or down by A $\$ 0.1 / \mathrm{kg}$ for each $1 \%$ of SKR greater or less than $33 \%$ SKR, respectively (Macadamia Processing Company, 2012). Costs for each replicate included pruning costs [hedging at $\mathrm{A} \$ 0.25$ /tree for each cut; limb removal at A $\$ 10.00 /$ tree (Australian Macadamia Society, 2012)], freight [A $\$ 0.08 / \mathrm{kg}$ NIS (O'Hare et al., 2004)] and the industry levy $[\mathrm{A} \$ 0.252 \mathrm{l} / \mathrm{kg}$ kernel (Australian Macadamia Society, n.d.)]. All other costs were assumed not to vary between the pruning treatments and the control. Harvesting costs, including dehusking, sorting, and handling, were assumed not to vary with yield as information from industry best practice groups indicated that harvest costs per hectare remained reasonably constant between seasons despite large fluctuations in yield (K. Quinlan, personal communication).

EXPERIMENT 3: THE EFFECT OF TOPPING ON 10-YEAR-OLD ' 344 ' TREES. The experimental site comprised 10 year-old ' 344 ' trees planted at $8 \times 4 \mathrm{~m}$ in north-south rows. Average tree height at the start of the study was $7.3 \mathrm{~m}$. Six pairs of three tree plots were selected across ten rows and trees from one plot in each pair were mechanically topped on 28 Nov. 2001 at $\approx 25^{\circ}$ from the vertical, creating a peak over the row at $6.5 \mathrm{~m}$; trees in the remaining plot in each pair were not topped (control). The height of the topping cut was guided by the top of a fiberglass pole positioned at $6.5 \mathrm{~m}$ above the ground in each tree. Plots were buffered as described in Expt. 2.

Yield, nut weight, and nut quality were measured for three seasons from 2002 to 2004 as in Expt. 2. Tree height was measured between September and October each season.

EXPERIMENT 4: THE EFFECTS OF TOPPING AND SELECTIVE LIMB REMOVAL ON 14-YEAR-OLD '344' TREES. This study was conducted on 14-year-old ' 344 ' trees planted at $8 \times$ $4 \mathrm{~m}$ in north-south rows. Average tree height at the start of the experiment was $9.7 \mathrm{~m}$. The tree canopies had met within the row to form a hedgerow. Trees were sprayed with 2-chloroethylphosphonic acid $\left(\right.$ Ethrel $^{\circledR}$; Bayer CropScience, Melbourne, Australia) at $600 \mathrm{ppm}$ on 12 May 2004 to promote fruit abscission (Trueman et al., 2002) so that harvesting could be completed before treatments were first applied in June 2004. Treatments included mechanically hedging the top of the tree (MT), selectively removing limbs at the top of the tree to reduce tree height (ST), removal of a codominant leader at 4 to $5 \mathrm{~m}$ above the ground (LR), and control trees $(\mathrm{C})$ that were unpruned apart from mechanical hedging of the sides of the hedgerow in Aug. 2005 and Sept. 2006, which was applied to all trees in the experiment.

In the MT treatment, two hedging cuts were made at the top of either side of the hedgerow at $\approx 45^{\circ}$, creating a peak over the tree row at around $8 \mathrm{~m}$. The height of the cut was guided as described in Expt. 3. Trees were topped on 30 June 2004 and 15 Nov. 2006. The average difference in tree height before and after the first pruning was $1.1 \mathrm{~m}$. In the $S T$ treatment, two to three limbs, each around 2 to $3 \mathrm{~m}$ in length, were removed from the top of the tree using a pole saw operated from an elevated platform. The limbs were cut as close as possible to a lateral branch. Trees were pruned between 22 and 24 June 2004. The average difference in tree height before and after pruning was $1.4 \mathrm{~m}$. In the LR treatment, a codominant leader was removed at around 4 to $5 \mathrm{~m}$ above the ground using a chain saw operated from an elevated platform. This treatment was applied on 8 July 2004.

The experimental design was a randomized block with unequal replication. There were six replications of the MT, ST, and C treatments and four of the LR treatment, laid out across 19 rows. The experimental unit was a three-tree plot and each plot was fully buffered as described in Expt. 2 .

Yield and nut weight were measured from 2005 to 2008 as described for Expt. 2.

Tree height was measured before treatment application in June 2004 and after treatment application in Aug. 2004, Aug. 2005, Oct. 2006, and Dec. 2007. Qualitative observations on post-pruning shoot growth were made from an elevated platform on 3 Nov. 2004, 1 Dec. 2004, and 9 Feb. 2005.

STATISTICAL ANALYSIS. Linear mixed models [ASReml-R software 
(Butler et al., 2007)] were used to analyze time (year) and site effects on yield (Expt. 1); pruning and time effects on yield, individual nut weight, nut quality, and tree dimensions (Expts. 2 to 4); and pruning effects on the PV of the gross margins for each treatment (Expt. 2). In the pruning experiments, treatment, time, and their interaction were included as fixed effects. In the yield survey in Expt. 1, time, site, and their interaction were included as fixed terms and lack of fit was included in the model as random deviations due to year of measurement. $F$-ratio tests (Wald method) and likelihood ratio tests were conducted to test the statistical significance of the fixed and random effects, respectively. Fisher's protected least significant difference test was used to compare means.

\section{Results}

EXPERIMENT 1: YIELD SURVEY. There was a significant effect of site on yield $(P<0.01)$ and a significant interaction between site and year $(P<$ $0.05)$. The predicted yields from the model indicated that yield decreased over the survey periods at three of the four sites (Fig. 1, Table 1). The data and predicted yields from the most crowded sites in a previous study (McFadyen et al., 2004) are also presented in Fig. 1 and Table 1. The rates of yield decline in the current study did not exceed that previously predicted at Fernleigh, the most crowded site in an earlier study, and were between $2 \%$ and $3 \%$ per year. The direction of yield change at Tregeagle changed from positive in the first study to negative in the longer monitoring period of the current study as the trees aged and the orchard became more crowded.

EXPERIMENT 2: THE EFFECTS OF SELECTIVE LIMB REMOVAL AND SIDEHEDGING ON 16-YEAR-OLD '246' TREES. There was a significant effect of treatment on yield $(P<0.05)$. Yield in the hedged treatment was, on average over all seasons, $12 \%$ lower than the control (Table 2, Fig. 2A). Yield in the limb removal treatment was higher than the control in 2000 and 2004, two and three years after pruning in 1998 and 2001, respectively [Fig. 2A $(P<0.05)]$, but was not significantly higher across all seasons [Table $2(P>0.05)]$.

There was a small effect of treatment on nut weight, which, across all

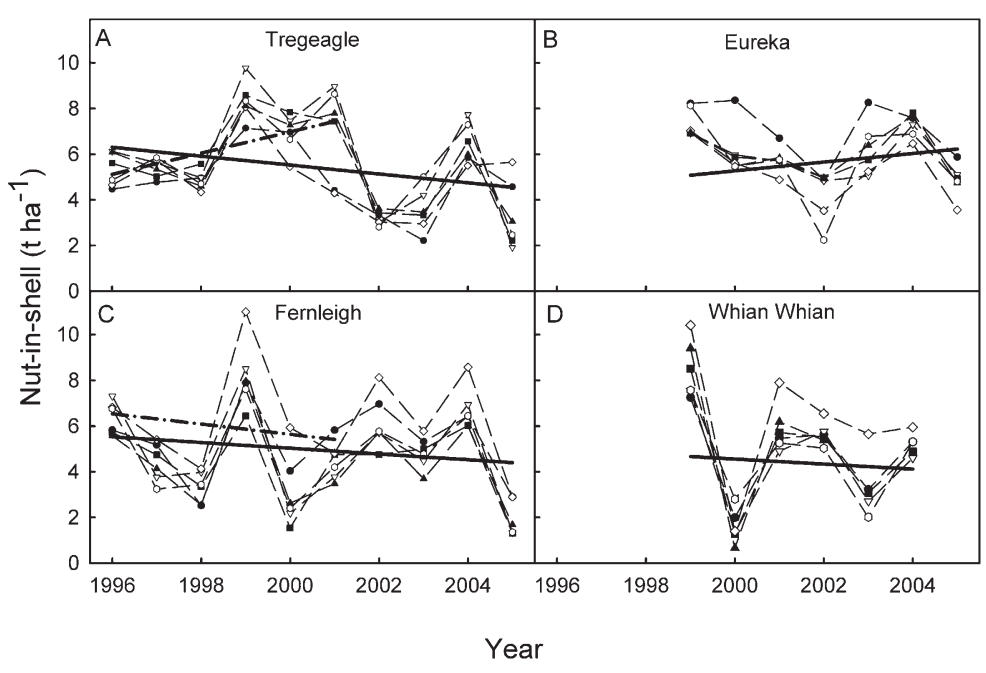

Fig. 1. Observed and predicted yields over time at four macadamia orchard sites near Lismore, Australia: (A) Tregeagle, (B) Eureka, (C) Fernleigh, and (D) Whian Whian, for periods between 1996 and 2005. Dashed lines represent actual yields from six plots of three (Tregeagle, Fernleigh, and Whian Whian) or four (Eureka) trees and solid lines represent predicted yields from a linear mixed model. Dash-dot lines in $A$ and $C$ represent predicted yields from an earlier analysis (McFadyen et al., 2004). Tree volume per hectare for each site increases from A to D. Tree volumes and the rate of the predicted changes in yields are given in Table $1 ; 1 \mathrm{t} \cdot \mathrm{ha}^{-1}=0.4461 \mathrm{ton} / \mathrm{acre}$.

Table 1. Rate of the predicted change in yield for mature macadamia orchards at four sites near Lismore, Australia, from the fixed part of a linear mixed model that was fitted to data in Fig. 1, and the mean tree volume per hectare for trees at each site at the beginning of the yield survey period.

\begin{tabular}{|c|c|c|c|}
\hline Site & $\begin{array}{l}\text { Period of } \\
\text { measurement }\end{array}$ & $\begin{array}{c}\text { Tree vol } \\
{\left[\text { mean } \pm \text { SE }\left(\mathrm{m}^{3} \cdot \mathrm{ha}^{-1}\right)\right]^{\mathrm{z}}}\end{array}$ & $\begin{array}{c}\text { Predicted yield change } \\
{\left[\text { slope } \pm \text { SE }\left(t \cdot h a^{-1} \text { per } y r\right)\right]^{y}}\end{array}$ \\
\hline Tregeagle $^{x}$ & 1996-2001 & $37,000 \pm 1,320$ & $0.47 \pm 0.40$ \\
\hline Tregeagle & 1996-2005 & $37,000 \pm 1,320$ & $-0.20 \pm 0.17$ \\
\hline Eureka & 1999-2005 & $41,800 \pm 1,110$ & $0.19 \pm 0.20$ \\
\hline Fernleigh $^{\mathrm{x}}$ & $1996-2001$ & $48,400 \pm 1,470$ & $-0.24 \pm 0.40$ \\
\hline Fernleigh & $1996-2005$ & $48,400 \pm 1,470$ & $-0.13 \pm 0.17$ \\
\hline Whian Whian & 1999-2004 & $51,100 \pm 1,310$ & $-0.16 \pm 0.20$ \\
\hline
\end{tabular}

${ }^{2}$ For six plots of three trees at each site, except at Eureka where there were six plots of four trees; $1 \mathrm{~m}^{3} \cdot \mathrm{ha}^{-1}=$ $14.2913 \mathrm{ft}^{3} /$ acre.

${ }^{\text {}}$ From lines fitted to data in Fig. 1; 1 tha $\mathrm{h}^{-1}=0.446 \mathrm{l}$ ton/acre.

${ }^{x}$ From McFadyen et al. (2004) in which Tregeagle and Fernleigh sites were identified as AI and FS respectively.

Table 2. Yield, individual nut weight, kernel recovery, and present value (PV) of gross margins [in Australian dollars (A\$)] based on a partial budget analysis of gross revenues and pruning and other costs, averaged across seven seasons for macadamia trees near Lismore, Australia, that were hedged, had limbs removed, or were controls. ${ }^{\mathrm{z}}$

\begin{tabular}{lcccc}
\hline Treatment & $\begin{array}{c}\text { Yield } \\
\left(\mathbf{t} \cdot \mathbf{h a}^{-1}\right)^{\mathbf{y}}\end{array}$ & $\begin{array}{c}\text { Individual } \\
\text { nut wt }(\mathrm{g})^{\mathrm{y}}\end{array}$ & $\begin{array}{c}\text { Kernel } \\
\text { recovery }(\%)\end{array}$ & $\begin{array}{c}\text { PV of gross } \\
\text { margin }(\mathrm{A} \$ \mathbf{h a})^{\mathbf{x}}\end{array}$ \\
\hline Control & $6.0 \mathrm{a}^{\mathrm{w}}$ & $6.5 \mathrm{a}$ & $36.5 \mathrm{a}$ & $10,200 \mathrm{a}$ \\
Hedged & $5.3 \mathrm{~b}$ & $6.8 \mathrm{~b}$ & $37.5 \mathrm{a}$ & $8,530 \mathrm{~b}$ \\
Limb removal & $6.3 \mathrm{a}$ & $6.8 \mathrm{~b}$ & $37.4 \mathrm{a}$ & $10,600 \mathrm{a}$ \\
SE & 0.21 & 0.11 & 0.60 & 593
\end{tabular}

${ }^{2}$ Mean and sE for six plots of three trees.

${ }^{y} 1 \mathrm{t} \cdot \mathrm{ha}^{-1}=0.4461 \mathrm{ton} / \mathrm{acre}, \mathrm{lg}=0.0353 \mathrm{oz}$.

Present value of gross margin (revenue from nut sales less pruning and other costs); A\$1/ha $=\mathrm{A} \$ 0.4047$ / acre.

"Mean separation by Fisher's protected least significant difference test. Means followed by a different letter are significantly different at $P<0.05$. 


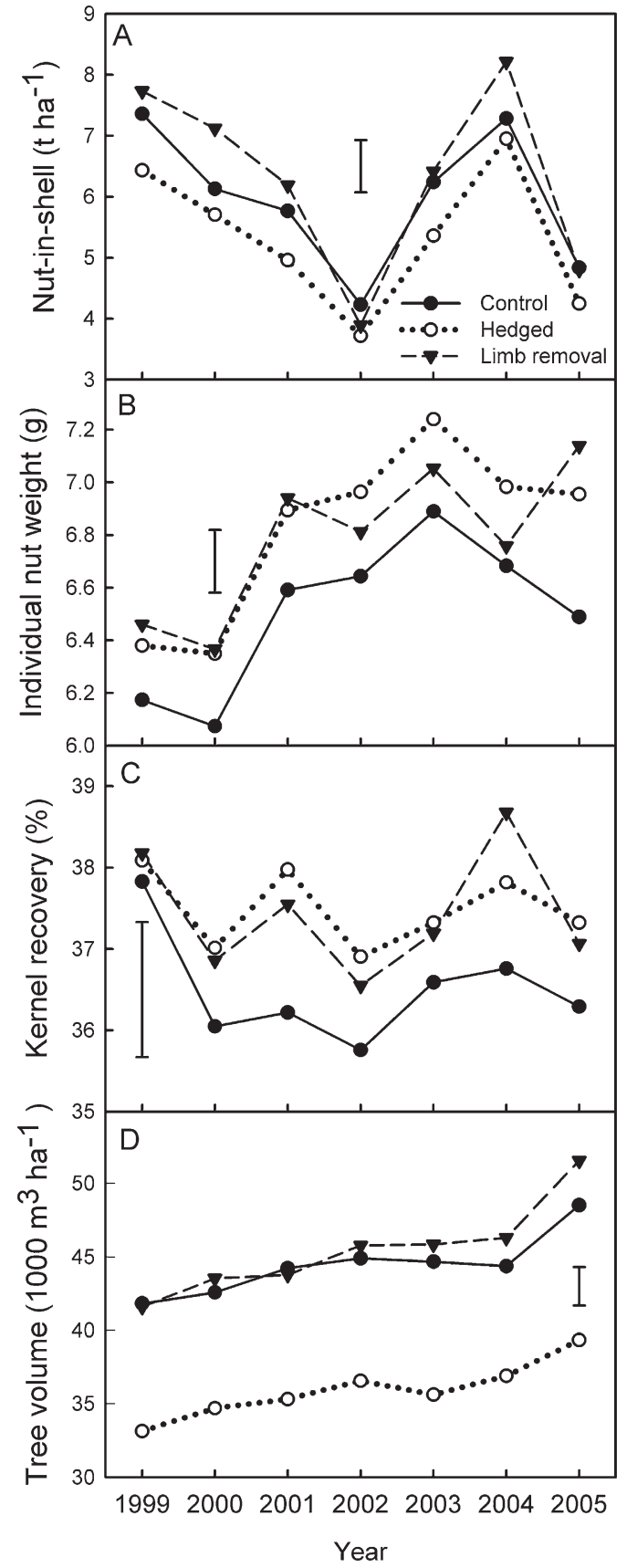

Fig. 2. (A) Yield, (B) individual nut weight, (C) kernel recovery, and (D) tree volume per hectare for macadamia trees near Lismore, Australia, that were hedged, had limbs removed, or were controls. Vertical bars represent Fisher's least significant difference at $P=0.05 ; 1 \mathrm{t} \cdot \mathrm{ha}^{-1}=0.4461 \mathrm{ton} /$ acre, $1 \mathrm{~g}=0.0353 \mathrm{oz}, 1 \mathrm{~m}^{3} \cdot \mathrm{ha}^{-1}=14.2913 \mathrm{ft}^{3} /$ acre

seasons, was $5 \%$ lower in the control than in the hedged and limb removal treatments [Table 2, Fig. 2B $(P<0.05)]$. There was also a tendency for kernel recovery to be slightly lower in the control compared with the other treatments, although not significantly [Fig. 2C $(P>0.05)]$. There were no treatment effects on unsound kernel or grade 1 kernel $[P>0.05$ (data not shown)].

There was no effect of treatment on tree height $[P>0.05$ (data not shown)]. Canopy width (data not shown), and consequently tree volume per hectare, was on average over the seasons $20 \%$ lower in the hedged treatment than in the control [Fig. 2D $(P<0.05)]$ and this relative difference varied little between seasons.

There was a significant effect of treatment on the PV of the gross margins [revenue from increased yield minus pruning and increased sundry costs $(P<0.05)]$. The average
PV of the gross margins over seven years for the hedged treatment was $\$ 1640 /$ ha less than the control [Table $2(P<0.05)]$, but the average $\mathrm{PV}$ of the gross margins for the limb removal treatment was not significantly different from the control $(P>$ $0.05)$. That is, the increased income in the limb removal treatment, because of higher yield and kernel recovery, was not sufficiently greater than the increased costs associated with this treatment to provide a better financial return than the control.

EXPERIMENT 3: THE EFFECT OF TOPPING ON 10-YEAR-OLD ' 344 ' TREES. There was a significant effect of topping on yield $(P<0.05)$ and a significant interaction between topping and year $(P<0.01)$. Yields of topped trees were $17 \%$ and $48 \%$ lower than control trees in the first and second years after topping, respectively (Fig. 3A). In the third year after topping, yield of topped trees had recovered and there was no difference between topped and control trees $(P>0.05)$. Tree height of topped trees also recovered to that of the control trees by the third year after topping [Fig. 3B $(P>0.05)]$.

There was a significant interaction between topping and year for nut weight, which was $12 \%$ greater in topped trees than in control trees in 2003 [Fig. 3C $(P<0.05)$ ], the year in which topping caused the greatest reduction in yield. Kernel recovery was lower in this year in topped trees [Fig. 3D $(P=0.09)]$. There were no effects of topping on unsound kernel or grade 1 kernel $[P>0.05$ (data not shown)].

EXPERIMENT 4: THE EFFECTS OF TOPPING AND SELECTIVE LIMB REMOVAL ON 14-YEAR-OLD ' 344 ' TREES. There was a significant effect of treatment on yield $(P<0.0001)$ and a significant interaction between treatment and year $(P<0.001)$. On average, across the seasons, yield was reduced by $51 \%$ and $21 \%$ for MT and LR treatments, respectively [Table 3 $(P<0.05)]$ but was not significantly lower in the ST treatment compared with the control $(P>0.05)$. Yield for ST trees was only significantly lower than control trees in 2006, the second year after treatment application [Fig. 4A $(P<0.05)]$. When the data for all years were included in the analysis, there were no significant differences between treatments in the first year of 


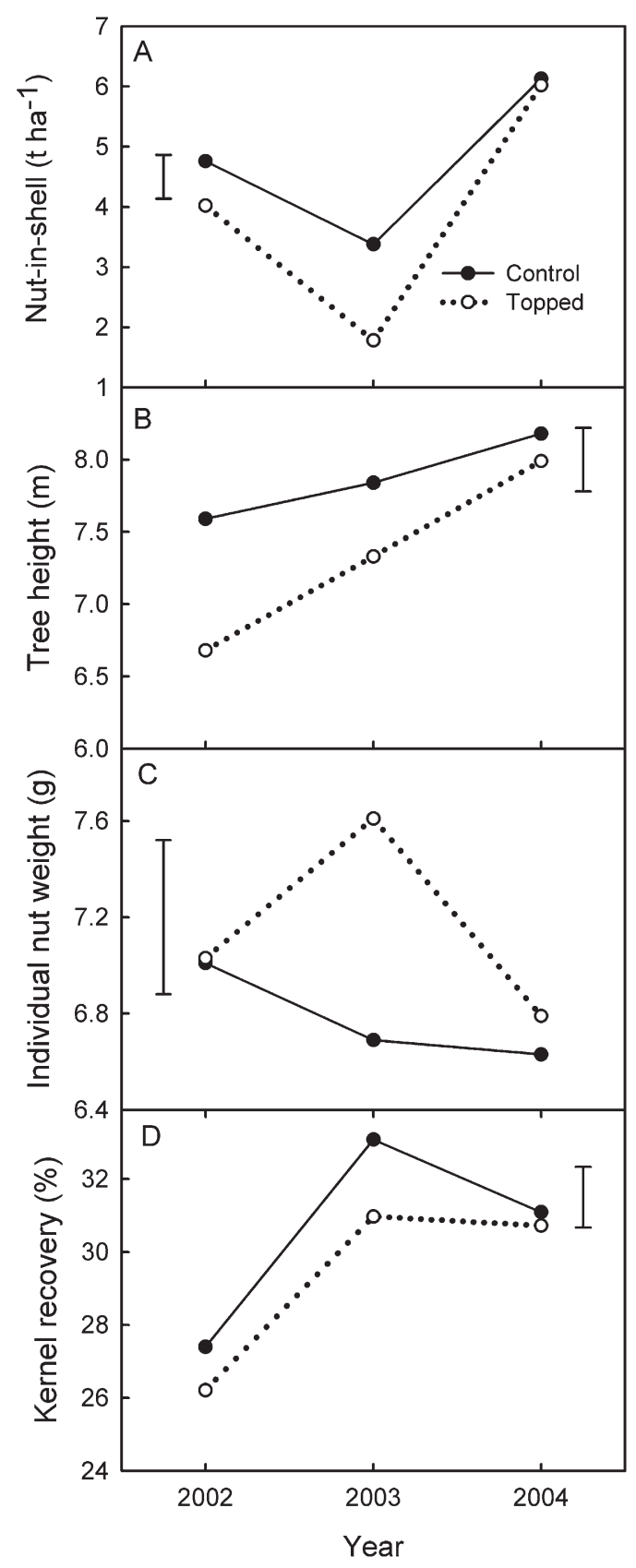

Fig. 3. (A) Yield, (B) tree height, (C) individual nut weight, and (D) kernel recovery for macadamia trees near Lismore, Australia, that were mechanically topped or untopped (control). Vertical bars represent Fisher's least significant difference test $(P=0.05) ; 1 \mathrm{t} \cdot \mathrm{ha}^{-1}=0.4461$ ton $/$ acre, $1 \mathrm{~m}=3.2808 \mathrm{ft}, 1 \mathrm{~g}=0.0353 \mathrm{oz}$.

the trial, despite yield in the MT treatment being less than half of the yield of the control. The lack of significance was probably due to the very low yields in that season across all treatments. When yield data were analyzed separately for 2005, yield of MT trees was significantly lower than the control trees $(P<0.05)$.

There was a significant interaction between treatment and year for nut weight [Fig. 4B $(P<0.05)]$. Nut weight tended to be slightly lower in control trees than in the other treatments, but the only significant difference in any one year was between control and ST trees in 2008.

Tree height increased most rapidly in the MT treatment and had recovered to that of the control in only two years after topping [Fig. 4C $(P>0.05)]$. Tree height also increased more rapidly in the ST treatment compared with the control although not as quickly as in the MT treatment. Among the pruned treatments, the increase in tree height was least for the LR treatment. Trees in this treatment at the end of the measurement period were still around $\mathrm{l} \mathrm{m}$ shorter than control trees $(P<0.05)$.

On 3 Nov. 2004, about three months after pruning, there was only a small amount of post-pruning shoot growth in all treatments. In the MT treatment, on a small proportion of the pruned branches, there was a short post-pruning flush that had hardened off. A new flush, with stems and leaves still expanding, was present on some of the other branches that had not previously flushed. Typically, each flush comprised six to seven shoots per cut branch. In the ST treatment, there was a small amount of new flush developing around some of the higher pruning cuts but no evidence of a completed post-pruning flush that was observed in the MT treatment. There was very little regrowth in the LR treatment. Total rainfall for June to Oct. 2004 recorded at the Center for Tropical Horticulture, Alstonville was $236 \mathrm{~mm}$, which is around half the long-term average for this period. By contrast, during Nov. 2004, $184 \mathrm{~mm}$ of rain fell, and on 14 Dec. 2004, we observed a marked increase in the amount of new flush on the pruned trees. A light green flush was observed on all branches in the MT treatment and multiple shoots had developed around the pruning cuts on some trees in ST and LR treatments. There was also new flush on the branches surrounding the removed limbs in these treatments, especially toward the outer and upper parts of the canopy. It seems likely that dry conditions in the first three months after pruning had delayed development of the postpruning flush. By 9 Feb. 2005, about seven months after pruning, there were multiple shoots around all pruning cuts, up to $1 \mathrm{~m}$ in length in all treatments. In the ST treatment, the two to three branches that had been removed by pruning had been replaced by a dense thicket of branches.

\section{Discussion}

The yield survey confirmed the relationship between orchard crowding and productivity from a previous study (McFadyen et al., 2004) and provided new information on yield change over the longer term. A limitation of 
Table 3. Yield and individual nut weight averaged across four seasons, for macadamia trees near Lismore, Australia, that were mechanically topped, had limbs removed from the upper canopy to reduce tree height, had a codominant leader removed or were controls. ${ }^{\mathrm{z}}$

\begin{tabular}{lcc}
\hline Treatment & Yield $\left(\mathbf{t} \cdot \mathbf{h a} \mathbf{a}^{-\mathbf{l}}\right)^{\mathrm{y}}$ & ${\text { Individual nut wt }(\mathbf{g})^{\mathrm{y}}}^{\mathrm{y}}$ \\
\hline Control & $4.3 \mathrm{a}^{\mathrm{x}}$ & 7.0 \\
Mechanically topped (MT) & $2.2 \mathrm{~b}$ & 7.1 \\
Selective removal of upper branches (ST) & $3.8 \mathrm{a}$ & 7.2 \\
Removal of codominant leader (LR) & $3.4 \mathrm{c}$ & 7.2 \\
SE (Control, MT, and ST) & 0.19 & 0.10 \\
SE (LR) & 0.23 & 0.13 \\
\hline
\end{tabular}

${ }^{2}$ Mean and SE for six plots of three trees (Control, MT, and ST) and four plots of three trees (LR).

${ }^{y} \mathrm{l} \cdot \mathrm{th}^{-1}=0.4461 \mathrm{ton} / \mathrm{acre} ; \mathrm{lg}=0.0353 \mathrm{oz}$

${ }^{x}$ Mean separation by Fisher's protected least significant difference test. Means followed by a different letter are significantly different at $P<0.05$

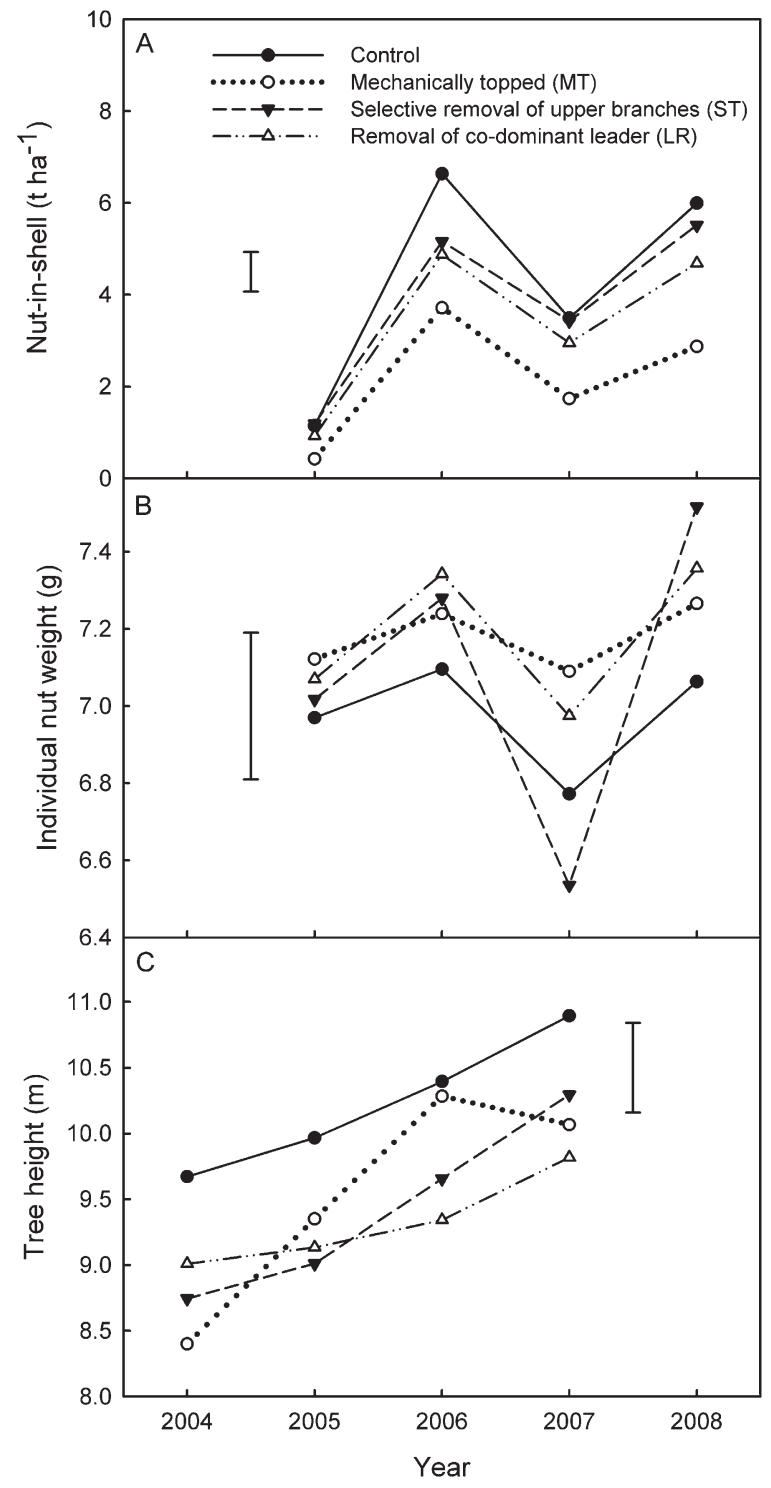

Fig. 4. (A) Yield, (B) individual nut weight, and (C) tree height for macadamia trees near Lismore, Australia, that were mechanically topped, had limbs removed from the upper canopy to reduce tree height, had a codominant leader removed, or were controls. Vertical bars represent Fisher's least significant difference test at $P=0.05$; $1 \mathrm{t} \cdot \mathrm{ha}^{-1}=0.4461 \mathrm{ton} / \mathrm{acre}, 1 \mathrm{~g}=0.0353 \mathrm{oz}, 1 \mathrm{~m}=3.2808 \mathrm{ft}$. the earlier study was that the evidence for yield decline depended on one site. In the current study, similar rates of yield decline were demonstrated at two other sites at comparable stages of crowding (Tregeagle and Whian Whian) to the yield decline site in McFadyen et al. (2004). At the Tregeagle site, the predicted yield change was positive over six years in the first study, but when yield was considered over the longer term of 10 years, there was an overall decline as trees aged and the orchard became more crowded. The initial tree volume of around $37,000 \mathrm{~m}^{3} \cdot \mathrm{ha}^{-1}$ at Tregeagle was within the confidence interval for the prediction of the relationship between tree volume per hectare and yield decline (McFadyen et al., 2004) and corresponds to a light interception of around 89\%. The absence of yield decline at Eureka probably reflects the lower initial tree volume compared with sites at Fernleigh and Whian Whian and the shorter monitoring period compared with the period for Tregeagle across the earlier (McFadyen et al., 2004) and present study. Our results highlight the need for long-term records to establish yield trends, particularly as an orchard approaches its production peak.

Removal of whole limbs from trees in Expt. 2 increased yields in the second or third season after pruning but the effect was short-lived. This may have been because the improvement in the canopy light environment was also transient. A similar yield response was observed in a study on pecan in which limb removal increased yield in only the second season out of three seasons following pruning (Lombardini, 2006). In that study, measurements of leaf area index and canopy light interception indicated that the pruned canopies quickly filled in with vigorous shoot growth so that within three seasons after pruning there was little difference in canopy density between treated and untreated trees. Shoot growth in macadamia is also favored by a high-light environment (Olesen et al., 2011). In six-year-old trees subjected to three manual pruning treatments of varying severity, there were no significant differences in light transmission to the orchard floor between 15 and 21 months after pruning (Olesen et al., 2011).

The lag of two to three seasons after pruning before yield increased 
relative to the control may reflect the time required to generate new flowering wood as most macadamia cultivars tend to flower on wood that is at least two years old (Nagao et al., 1994; Olesen et al., 201 1; Wilkie et al., 2009).

The economic analysis indicated that, despite the increase in yield and kernel recovery, limb removal did not provide a greater financial return relative to the control because of the increased costs associated with limb removal.

Annual hedging reduced yield in the first year after hedging by $13 \%$ and by $12 \%$ on average over seven years compared with unpruned control trees. Tree volume per hectare of hedged trees was 20\% lower than unpruned trees, and it is possible that differences in light interception contributed to the effects on yield. It may also be that hedging in October, a popular industry hedging time, which is around the time of early fruit development interfered with fruit set through competition between fruit and the post-pruning flush (McFadyen et al., 2011).

The effect of annual hedging on 16-year-old '246' trees in this study was greater than that for nine-yearold ' 344 ' trees in an earlier study (McFadyen et al., 2005). In that study, there were no differences in yield between hedged and unhedged trees until the fifth and sixth years after hedging commenced. It may have been that the younger trees were able to recover the leaf area removed in hedging more quickly than the older trees as young trees tend to grow more vigorously after pruning than older trees (Mika, 1986). There is some support for this in the patterns of tree volume over time in each study. In the current study, hedging reduced tree volume by $20 \%$ in the first year after hedging and this relative difference was more or less maintained over the seven years. In the earlier study, there was not a substantial reduction in tree volume until after the fourth season. This reduction followed a very high cropping year, which may have limited shoot growth and recovery of the canopy (Edson et al., 1993; Palmer 1992; Wilkie 2009).

One concern with regular hedging at the same point in the canopy over the long term is that it does not allow for the renewal of flowering stems, which, as already mentioned, are stems that are, for most cultivars, at least two years old. We expected that a decline in flowering stems in hedged trees would be reflected in a widening gap in yield between hedged and control trees; however, this did not happen in this study. Possibly, sufficient flowering stems were retained in the upper canopy that was not reached by the hedger. It may also be that there was too little time to exhaust potential flowering nodes.

Hedging caused a significant reduction in the gross margin per hectare relative to the control which, during the course of the experiment, approached full canopy closure. The financial analysis did not take into account the value of the management benefits of maintaining an open interrow because the value of these benefits is difficult to measure and therefore uncertain. Nevertheless, these factors will influence the choice of management practice in a working orchard.

The reduction in yield and ultimately income due to hedging might be minimized by hedging at a time that the post-hedging shoot growth did not overlap with early fruit development and reduce fruit set (McFadyen et al., 2012).

Mechanically topping trees caused a substantial reduction in yield in both experiments. Topping was followed by vigorous shoot growth at the top of the tree and tree height was recovered to that of the control within two to three years of topping. A similar rate of recovery in tree height after topping was reported for citrus (Raciti et al., 1981). In Expt. 3, topping caused a larger reduction in the second year after topping $(48 \%)$ than in the first year $(16 \%)$. The reduction in the first year was possibly due to a combination of direct removal of fruit in the topping operation and an effect on fruit set. We had anticipated that the timing of topping, in late November at around 10 weeks post anthesis and at the end of the normal premature fruit drop period (Sakai and Nagao, 1984; Trueman and Turnbull, 1994), would minimize any effect of pruning on fruit set. In macadamia, light tip-pruning of trees in late November resulted in less fruit drop and higher yield than pruning trees in September or October around flowering and early fruit development (McFadyen et al., 2012). However, in citrus, severe pruning that was applied after the premature fruit drop period still reduced fruit number (Eissenstat and Duncan, 1992). The increase in response to topping in the second year may have been caused by subsequent regrowth flushes inhibiting flowering. Wilkie et al. (2010) demonstrated that the synchrony of the flush arising from pruning branch tips in spring was maintained over three consecutive flushes and inhibited the production of racemes in winter.

In Expt. 4, topping was carried out in June to avoid removal of fruit and to allow the post-pruning flush time to expand before fruit set. Despite this, yield of MT trees in the first season after topping was less than half that of control trees. From our observations on the timing of the development on post-pruning flush, it appears there was a new flush underway in these trees from early November and this may have reduced fruit set.

Selectively removing limbs at the top of the tree gave a similar reduction in tree height as achieved with mechanical topping but with much less effect on yield, and tree height recovered more slowly so that three years after application trees were still around $0.7 \mathrm{~m}$ shorter than the control. However, the dense regrowth around the original cuts would make reapplication of the treatment very difficult. Removal of a main leader had the most lasting effect on tree height although the average $22 \%$ reduction in yield over four years makes it an unattractive option for growers.

Pruning also affected nut characteristics. Nut weight tended to be higher in pruned trees than in unpruned trees. This result is comparable with effects on fruit and nut size in pruning studies in other crops (Kretchman and Jutras, 1962; Mika, 1986; Morales et al., 2000; Thorp and Stowell, 2001; Worley, 1991) and can be attributed to reductions in crop load (Mika, 1986) and improvements in light penetration (Jackson, 1980).

The association between nut weight and kernel recovery varied between experiments. In the second experiment, higher nut weights in the pruned treatments were associated with higher kernel recoveries, but in the third experiment, higher nut weight in pruned trees was associated with lower kernel recovery. Interestingly, both associations have been reported previously. Cross pollination and temperature treatments that increased nut weight also increased 
kernel recovery (Stephenson and Gallagher, 1986; Wallace et al., 1996) but reducing crop load by removing racemes increased nut weight and reduced kernel recovery (Wilkie, 2009). McFadyen et al. (2004) also showed that kernel recovery decreased with decreasing crop load. It may be that different environmental factors affect assimilate partitioning in antagonistic ways. This warrants further investigation.

Our study has confirmed that yield decline is associated with orchard crowding and high levels of shading. Pruning that removed several large limbs to reduce shading increased yield but the improvement was shortlived and was not cost-effective. Although yield was not cost-effectively maintained or increased by pruning in mature macadamia orchards using the methods evaluated in these experiments, the need still exists to control tree size to avoid the management problems caused by orchard crowding. Side-hedging and topping contained tree size but not without a significant reduction in yield, especially in the case of topping. The effect of light regular side-hedging on yield may be minimized by timing hedging after the premature fruit drop period (McFadyen et al., 2012). However, it is not clear if the effect of more severe pruning as occurs with topping can be similarly mitigated. Despite attempts in the current study to time the topping operation to avoid an effect on fruit abscission, yield was still substantially reduced. Further work is required to understand the mechanisms involved in the yield response to topping and ultimately improve outcomes.

\section{Literature cited}

Australian Macadamia Society. 2012. Special feature: Canopy management. Austral. Macadamia Soc. News Bul. 40(2): 62-76.

Australian Macadamia Society. n.d. Australian Macadamia Society, Lismore, Australia. 4 June 2012. <http://macadamias. org $>$.

Bevington, K.B. and P.E. Bacon. 1978. Effect of hedging on the productivity of Valencia orange trees. Austral. J. Expt. Agr. Anim. Husb. 18:591-596.

Butler, D., B.R. Cullis, A.R. Gilmour, and B.J. Gogel. 2007. ASReml-R reference manual. Queensland Dept. Primary Ind. Fisheries, Brisbane, Australia.
Charles-Edwards, D.A., D. Doley, and G.M. Rimmington. 1986. Modelling plant growth and development. Academic Press, Sydney, Australia.

Cull, B.W. 1983. Proteaceae, p. 150-159. In: P.E. Page (ed.). Tropical tree fruits for Australia. Queensland Dept. Primary Ind., Brisbane, Australia.

Edson, C.E., G.S. Howell, and J.A. Flore. 1993. Influence of crop load on photosynthesis and dry matter partitioning of Seyval grapevines I. Single leaf and whole vine response pre- and post-harvest. Amer. J. Enol. Viticult. 44:139-147.

Eissenstat, D.M. and L.W. Duncan. 1992. Root growth and carbohydrate responses in bearing citrus trees following partial canopy removal. Tree Physiol. 10:245-257.

Ferguson, L., J. Maranto, and R. Beede. 1995. Mechanical topping mitigates alternate bearing of 'Kerman' pistachios (Pistacia vera L.). HortScience 30: 1369-1372.

Fucik, J.E. 1977. Hedging and topping in Texas grapefruit orchards. Proc. Intl. Soc. Citricult. 1:172-176.

Fucik, J.E. 1988. First year responses of grapefruit trees to semi-selective pruning. J. Rio Grande Valley Hort. Soc. 41:83-88.

Jackson, J.E. 1980. Light interception and utilisation by orchard systems. Hort. Rev. 2:208-267.

Kallsen, C.E. 2005. Topping and manual pruning effects on the production of commercially valuable fruit in a midseason navel orange variety. HortTechnology 15:335-341.

Kretchman, D.W. and P.J. Jutras. 1962. The influence of pruning on size and quality of Florida grapefruit. Proc. Florida State Hort. Soc. 75:35-42.

Lombardini, L. 2006. One-time pruning of pecan trees induced limited and shortterm benefits in canopy light penetration, yield and nut quality. HortScience 41:1469-1473.

Macadamia Processing Company. 2012. 2012 Notional price table at 10\% moisture content. Macadamia Processing Company, Alphadale, New South Wales. 4 June 2012. <http://www.macadamia. au.com/pdf/MPC.SPEC.NIS.0lb_notional_ pricetable_2012_Y.pdf>.

McFadyen, L.M., S.G. Morris, C.A. McConchie, and M.A. Oldham. 2005. Effect of hedging and tree removal on productivity of crowding macadamia orchards. Austral. J. Expt. Agr. 45:725-730.

McFadyen, L.M., S.G. Morris, M.A. Oldham, D.O. Huett, N.M. Meyers,
J. Wood, and C.A. McConchie. 2004. The relationship between orchard crowding, light interception, and productivity in macadamia. Austral. J. Agr. Res. 55:1029-1038.

McFadyen, L.M., S.G. Morris, M.A. Oldham, C.A. McConchie, D.O. Huett, N.M. Meyers, and J. Wood. 2003. Canopy management in macadamia. Proc. Second Intl. Macadamia Symp. p. 139-142.

McFadyen, L.M., D. Robertson, M. Sedgley, P. Kristiansen, and T. Olesen. 2011. Post-pruning shoot growth increases fruit abscission and reduces stem carbohydrates and yield in macadamia. Ann. Bot. (Lond.) 107:993-1001.

McFadyen, L., D. Robertson, M. Sedgley, P. Kristiansen, and T. Olesen. 2012. Time of pruning affects fruit abscission, stem carbohydrates and yield of macadamia. Funct. Plant Biol. 39:481-492.

Mika, A. 1986. Physiological responses of fruit trees to pruning. Hort. Rev. 8:337378 .

Morand, T. 1994. Soil landscapes of the Lismore-Ballina 1:100 000 sheet report. Soil Conservation Serv., Sydney, Australia.

Morales, P., F.S. Davies, and R.C. Littell. 2000. Pruning and skirting affect canopy microclimate, yields, and fruit quality of 'Orlando' tangelo. HortScience 35:30-35.

Nagao, M.A., E.B. Ho-a, J.M. Yoshimoto, E.R. Yoshimura, E. Notley, and L.H. Fuchigami. 1994. Relationship between vegetative flushing and flowering of Macadamia integrifolia in Hawaii. Sci. Hort. 42:47-54.

O'Hare, P., K. Quinlan, R. Stephenson, and N. Vock. 2004. Growing guide: Macadamia grower's handbook. Queensland Dept. Primary Ind., Brisbane, Australia.

Olesen, T. 2005. The timing of flush development affects the flowering of avocado (Persea americana) and macadamia (Macadamia integrifolia). Austral. J. Agr. Res. 56:723-729.

Olesen, T., D. Huett, and G. Smith. 2011. The production of flowers, fruit and leafy shoots in pruned macadamia trees. Funct. Plant Biol. 38:327-336.

Palmer, J.W. 1992. Effects of varying crop load on photosynthesis, dry matter production and partitioning of Crispin/ M.27 apple trees. Tree Physiol. 11:19-33.

Raciti, G., P. Spina, A. Scuderi, and F. Intriglio. 1981. Three years of mechanical pruning of citrus in Italy. Proc. Intl. Soc. Citricult. 1:175-180.

Robertson, D., L. McFadyen, and J. Bright. 2012. Grower trials in tree removal. Austral. Macadamia Soc. News Bul. 40(2):87-91. 
Sakai, W.S. and M.A. Nagao. 1984. Fruit growth and abscission in Macadamia integrifolia. Physiol. Plant. 64:455460.

Stephenson, R.A. and E.C. Gallagher. 1986. Effects of temperature during latter stages of nut development on growth and quality of macadamia nuts. Sci. Hort. 30:219-225.

Thorp, T.G. and B. Stowell. 2001. Pruning height and selective limb removal affect yield of large 'Hass' avocado trees. HortScience 36:699-702.

Trueman, S.J., C.A. McConchie, and C.G.N. Turnbull. 2002. Ethephon promotion of crop abscission for unshaken and mechanically shaken macadamia. Austral. J. Expt. Agr. 42:1001-1008.

Trueman, S.J. and C.G.N. Turnbull. 1994. Fruit set, abscission and dry matter accumulation on girdled branches of macadamia. Ann. Bot. (Lond.) 74:667-674.

Wallace, H.M., V. Vithanage, and E.M. Exley. 1996. Effect of supplementary pollination on nut set of Macadamia (Proteaceae). Ann. Bot. (Lond.) 78:765-773.

Whitney, J.D., T.A. Wheaton, W.S. Castle, and D.P.H. Tucker. 1983. Citrus tree size management affects fruit yields and mechanical harvesting efficiency. Trans. Amer. Soc. Agr. Eng. 26:704-709.

Wilkie, J.D. 2009. Interactions between the vegetative growth, flowering and yield of macadamia (Macadamia integrifolia, $M$. integrifolia $\times M$. tetraphylla), in a canopy management context. Univ. of New England, Armidale, Australia, PhD Diss.

Wilkie, J.D., M. Sedgley, S. Morris, S. Muldoon, and T. Olesen. 2009. Characteristics of flowering stems and raceme position in macadamia. J. Hort. Sci. Biotechnol. 84:387-392.

Wilkie, J.D., M. Sedgley, and T. Olesen. 2010. The timing of pruning affects flushing, flowering and yield of macadamia. Crop Pasture Sci. 61:588-600.

Worley, R.E. 1985. Effects of hedging and selective limb pruning of Elliot, Desirable, and Farley pecan trees under three irrigation regimes. J. Amer. Soc. Hort. Sci. 110:12-16.

Worley, R.E. 1991. Selective limb pruning intensity influences mature pecan tree and nut characteristics. HortScience 26:126-129.

Worley, R.E. and B. Mullinix. 1997. Selective limb pruning of large pecan trees reduces yield but improves nut size and tree characteristics. HortScience 32:50-52. 